\title{
Seasonal and Regional Variations in Metal Contamination and Condition Indicators in Yellow Perch (Perca flavescens) along Two Polymetallic Gradients. II. Growth Patterns, Longevity, and Condition
}

\author{
Gregory Pyle, ${ }^{1}$ Patrick Busby, ${ }^{2}$ Charles Gauthier, ${ }^{3}$ James Rajotte, ${ }^{2}$ \\ and Patrice Couture ${ }^{3}$ \\ ${ }^{1}$ Department of Biology, Nipissing University, North Bay, ON, Canada; \\ ${ }^{2}$ Department of Biology, Laurentian University, Sudbury, ON, Canada; ${ }^{3}$ Institut \\ National de la Recherche Scientifique, Centre Eau, Terre et Environnement \\ (INRS-ETE), QC, Canada
}

\begin{abstract}
Wild yellow perch (Perca flavescens) were sampled from five lakes in each of two metal contamination gradients in Sudbury, Ontario, Canada ( $n=1324)$ and RouynNoranda, Québec, Canada $(n=1125)$ in the spring and summer of 2002 and 2003, respectively, in order to examine growth patterns, longevity, and the influences of season and region on fish condition. Fish from Rouyn-Noranda began rapid growth at a young age, whereas fish from Sudbury lakes showed slow growth rates between ages $0-3$, after which growth rates improved. Fish from contaminated lakes grew faster and died younger than fish from reference lakes in both contamination gradients. Fish from Sudbury had lower condition than in Rouyn-Noranda, higher condition occurred in summer than spring, and fish from contaminated lakes had lower condition than those from cleaner lakes. Tissue $\mathrm{Zn}$ concentrations were correlated with fish condition and showed strong temporal stability. However, it is more likely that $\mathrm{Zn}$ covariates, such as $\mathrm{Cd}$ or $\mathrm{Cu}$ (which were more temporally variable) influenced condition, suggesting that long-term, broad-scale processes are more important than short-term, lake-specific processes for establishing growth patterns, longevity, and fish condition in metal-contaminated systems. Results from this study reveal that fish condition must be interpreted in the light of regional, seasonal, and other factors that can potentially influence fish growth patterns. Ecological risk assessments that fail to take these factors into account may draw erroneous conclusions about risk to indigenous populations.
\end{abstract}

Address correspondence to G. Pyle, Ph.D., Department of Biology, Nipissing University, Box 5002, North Bay, ON P1B 8L7, Canada. E-mail: gregp@nipissingu.ca 


\section{Metal Effects on Growth and Condition in Wild Yellow Perch}

Key Words: yellow perch, growth, longevity, fish condition, metals, gradient analysis.

\section{INTRODUCTION}

The relationship between environmental metal contamination and fish condition has been difficult to establish because of myriad influences of contamination level, geographic region, and season. The literature provides examples of lower fish condition in metal contaminated lakes relative to reference lakes (Leis and Fox 1994; Laflamme et al. 2000; Lohner et al. 2001; Levesque et al. 2002; Rajotte and Couture 2002; Levesque et al. 2003; Bervoets and Blust 2003; Couture and Rajotte 2003). Other studies report higher fish condition in metal-contaminated lakes than in reference lakes (Farkas et al. 2003), possibly owing to increased lipids and triglycerides in tissues of metal-exposed fish (Pyle et al. 2005; Bennett and Janz 2007). In most cases, fish were only sampled once and the influence of season was completely ignored. Audet and Couture (2003) showed that yellow perch from a metalcontaminated lake had lower condition in the spring and fall, but higher condition in the summer, than fish from a reference lake. This result highlights the importance of understanding seasonal variability in fish condition before drawing conclusions on the influence of metal exposure on condition, especially when the variability associated with season (or some other influential variable) is much larger than that associated with metal contamination.

Human activities in the industrial regions of Sudbury, Ontario and Rouyn-Noranda, Québec have led to wide-scale metal contamination of aquatic systems. Metal mining and smelting in the Sudbury area has been taking place since 1883 and has resulted in the acidification and metal contamination of some 7000 lakes in a $17,000 \mathrm{~km}^{2}$ industrial zone-of-influence (Keller et al. 1992). Copper smelting in Rouyn-Noranda has been ongoing for approximately 80 years, and has led to metal contamination of nearby lakes. (Couillard et al. 1993). Both of these industrial areas provide a unique opportunity to explore the complex relationships among environmental and tissue metal contamination, season, region, and other factors that could influence fish condition by exploiting metal-contamination gradients. Recent studies on wild yellow perch (Perca flavescens) populations in lakes surrounding these industrial regions have reported on the influence of different biotic and abiotic factors on fish condition (Laflamme et al. 2000; Levesque et al. 2002; Rajotte and Couture 2002; Eastwood and Couture 2002; Levesque et al. 2003; Couture and Rajotte 2003; Audet and Couture 2003; Couture and Kumar 2003; Taylor et al. 2004; Pyle et al. 2005), but without considering the basic statistical assumptions of standard fish condition models outlined earlier or the combined influences of the various factors on fish condition.

The purpose of this study was to evaluate the single and combined influences of season, geographic region, and tissue metal $(\mathrm{Cd}, \mathrm{Cu}, \mathrm{Ni}, \mathrm{Se}$, and $\mathrm{Zn}$, which are the "metals of concern" in these two gradients) accumulation on growth patterns and condition of wild yellow perch populations from two metal-contamination gradients by using an integrated approach (Patterson 1992). Yellow perch is an important fish species in northern Canadian lakes, especially in metal-contaminated industrial 


\section{G. Pyle et al .}

regions. These fish are tolerant to metals (Eaton et al. 1992) widely distributed (Scott and Crossman 1973), and occur as top predators in metal-contaminated lakes and as an important prey in other lakes (Pyle et al. 2005). Although relatively little research has been done to evaluate environmental metal effects in this ecologically important fish species, a growing number of ecotoxicological studies have begun focusing on yellow perch (Laflamme et al. 2000; Levesque et al. 2002; Eastwood and Couture 2002; Levesque et al. 2003; Couture and Rajotte 2003; Audet and Couture 2003; Pyle et al. 2005).

\section{MATERIALS AND METHODS}

\section{Study Lakes and Fish Sampling}

This work is part of a much larger study. Consequently, sampling techniques, water quality data, yellow perch tissue metal concentrations (specifically, $\mathrm{Cd}, \mathrm{Cu}, \mathrm{Ni}$, $\mathrm{Se}$, and $\mathrm{Zn}$ ), and a map of the study area are reported elsewhere (Couture et al. 2008a). Briefly, five lakes were sampled in each of two metal-contaminated regions in Sudbury, ON, and Rouyn-Noranda, QC, Canada. Each gradient contained two clean lakes, one intermediate lake, and two metal-contaminated lakes. Sudbury-area lakes (S) were sampled in the spring and summer of 2002, and Rouyn-Noranda lakes $(\mathrm{RN})$ were sampled in the spring and summer of 2003. Within each region, lakes were ranked according to metal concentration, such that the least contaminated lakes were given a rank of 1 or 2 , the most contaminated lakes were given a rank of 4 or 5 , and intermediate lakes were given a rank of 3 . Therefore, S3 represents the intermediate lake in the Sudbury region, and RN5 represents one of the two most contaminated lakes sampled in Rouyn-Noranda.

A fish sampling strategy was devised to increase the probability of sampling the entire size and age range of yellow perch from each lake in both spring and summer sampling events. To accomplish this, fish were sampled using minnow traps, seine nets, and by angling. Because each lake was sampled in both the spring and summer, we established $a$ priori that each lake would be sampled for at least two days during each seasonal sampling event to ensure that all yellow perch age or size classes available in the lake were represented in our sample of at least 120 fish per lake per season. Once caught, fish were transported live in aerated lake water back to the laboratory for further processing. Laboratory facilities were always available in the vicinity of study lakes; therefore, fish were never transported for longer than two hours after being removed from any lake.

Fish were aged by counting annuli from the left-side opercular bone. Opercula were removed and submersed in boiling distilled water for $10 \mathrm{~s}$, which allowed for the easy removal of overlying skin. Cleaned opercular bones were air dried and observed under a dissection microscope. Annuli were then counted by the same technician for all fish in the study $(n=2449)$. A random subsample of opercular bones was sent to an outside fish aging contractor for verification (Labman Aging Services, Cochrane, $\mathrm{ON})$. Ages determined by our technician were within $10 \%$ of those determined by the contractor. 


\section{ANALYSIS OF FISH CONDITION}

\section{Traditional Fish Condition Metrics}

Individual fish weight $\left(W_{i}\right)$ can be estimated from its length $\left(L_{i}\right)$ by using the following equation:

$$
W_{i}=a L_{i}^{b},
$$

where, $a$ and $b$ are regression parameters (intercept and slope, respectively) estimated from a double-log weight-length plot, such that:

$$
\log _{10}\left(W_{i}\right)=\log _{10} a+b \log _{10}\left(L_{i}\right)+\varepsilon_{i}
$$

where $\varepsilon_{i}$ is the residual for fish $i$. Traditional condition metrics $K_{F}$ and $K_{n}$ are based on a rearrangement of Eq. (1):

$$
a=\frac{W_{i}}{L_{i}^{b}} .
$$

Consequently, $a$, the intercept of the log-log weight-length plot, represents a measure of fish condition, $K$. By substituting $K$ for $a$ in Eq. (3), and different values for $b, K_{F}$ (where $b=3$ ) and $K_{n}$ (where $b$ is estimated from a separate regression of a single comparative sample of fish) can be calculated. Often, $K_{F}$ and $K_{n}$ are multiplied by some constant factor of 10 such that their magnitude approximates unity.

\section{Integrated Model Development}

Le Cren (1951) proposed a two-step least-squares approach for analyzing weightlength relationships toward assessing condition in European perch (Perca fluviatilis). The advantage of the least-squares approach is that many of the assumptions that are difficult to meet in traditional condition analysis are somewhat mitigated. Patterson (1992) devised an alternative least-squares approach, following Le Cren, which involves the construction of sophisticated, integrated models that attempt to account for variability associated with fish condition from a wide range of sources. The advantage of using an integrated model over traditional condition measures is that it overcomes many of the assumptions associated with traditional condition metrics, and it provides detailed information on the influence of several factors simultaneously as they affect fish condition. Moreover, nominal factors, such as season or location, can be analyzed at the same time as continuous factors, such as environmental metal contamination.

The integrated, least-squares model used in this study to evaluate fish condition follows Patterson (1992). Briefly, this approach constructs complex models starting from the simple model described in Eq. (2) by adding terms corresponding to each independent variable thought to influence $W_{i}$. Each nominal factor (location, season, etc.) will contribute to the intercept for the entire model. Continuous factors, such as tissue metal concentrations, can be included in the model as independent variables, and the significance of their inclusion and their interactions with other model constituents can be tested using analysis of covariance (ANCOVA). Therefore, an integrated model that includes one nominal factor such as season, $a[s]$, and one continuous factor such as tissue metal concentration, $m\left(X_{i}\right)$, to account for variation 


\section{G. Pyle et al .}

of $W_{i}$, would take the following form:

$$
\log _{10}\left(W_{i}\right)=\log _{10}(\mathrm{a}[0])+\log _{10}(\mathrm{a}[\mathrm{s}])+\mathrm{m}\left(X_{i}\right)+\operatorname{blog}_{10}\left(L_{i}\right)+\varepsilon_{i}
$$

where, $a[0]$ is the intercept for the complete model. Regression parameter estimates provide information about the effect of each parameter on fish condition, such that each parameter estimate represents the logarithmic geometric mean deviation of $K$ from unity in each comparative group (Patterson 1992). Raw coefficients are preferable to back-transformed coefficients because back-transformation leads to non-normal distributions.

The model is constructed by including all variables thought to have an influence on $W_{i}$. The significance of each independent variable is tested, and nonsignificant variables are removed individually in a stepwise fashion. Once the complete model is constructed, significance of interacting terms, such as $b[s] * \log _{10}\left(L_{i}\right)$ or $b[s] * m\left(X_{i}\right) * \log _{10}\left(L_{i}\right)$, can then be tested using ANCOVA.

The goal of this study was to evaluate the single and combined influences of position along the contamination gradient (i.e., contamination rank from 1-5 in each region, $a[k]$, where $k=1-5)$, region $(a[r]$, where $\mathrm{r}=$ Sudbury or Rouyn-Noranda), season $(a[s]$, where $\mathbf{s}=$ spring or summer), and tissue metal concentration (where tissues include gut contents, $G$, kidney, $K$, and liver, $L$; and metals include $\mathrm{Cd}, \mathrm{Cu}$, $\mathrm{Ni}$, Se, and $\mathrm{Zn}$ ). Because tissue metal concentrations were only measured in a subset of all the fish sampled, it was not possible to investigate all interaction permutations among rank, region, and season with respect to tissue metal concentrations. Therefore, two full integrated models were constructed: Model I included all the sampled fish $(n=2449)$ and is represented by Eq. (5), and Model II included only those fish where tissue metal concentration data were available $(n=338)$, and is represented by Eq. (6), as follows:

$$
\log _{10}\left(W_{i}\right)=\log _{10}(a[0])+\log _{10}(a[k])+\log _{10}(a[r])+\log _{10}(a[s])+b \log _{10}\left(L_{i}\right)+\varepsilon_{i},
$$

and,

$$
\begin{aligned}
\log _{10}\left(W_{i}\right)= & \log _{10}(a[0])+\log _{10}(a[r])+\log _{10}(a[s]) \\
& +G_{C d}\left(X_{i}\right)+G_{C u}\left(X_{i}\right)+G_{N i}\left(X_{i}\right)+G_{S e}\left(X_{i}\right)+G_{Z n}\left(X_{i}\right) \\
& +K_{C d}\left(X_{i}\right)+K_{C u}\left(X_{i}\right)+K_{N i}\left(X_{i}\right)+K_{S e}\left(X_{i}\right)+K_{Z n}\left(X_{i}\right) \\
& +L_{C d}\left(X_{i}\right)+L_{C u}\left(X_{i}\right)+L_{N i}\left(X_{i}\right)+L_{S e}\left(X_{i}\right)+L_{Z n}\left(X_{i}\right)+b \log _{10}\left(L_{i}\right)+\varepsilon_{i} .
\end{aligned}
$$

\section{Data Handling}

Yellow perch length and weight data were $\log _{10}$-transformed to normalize distributions. Bivariate relationships were analysed first using simple linear regression. Slopes were compared using ANCOVA. However, whenever a nonlinear model provided a better fit to the data, polynomial regression was used instead, but never beyond third order. Integrated least-squares condition models were constructed as described earlier.

To estimate fish longevity in each lake, lakes were sampled in two seasons (spring and summer) and aged using opercular bones. (for details, see Couture et al. 2008a). Maximum fish age was determined in fish collected from each lake in each season. In any given lake, longevity was conservatively estimated by calculating the average age of the oldest fish between the two seasons. This method for establishing longevity 


\section{Metal Effects on Growth and Condition in Wild Yellow Perch}

does not account for the range of variability of maximum age for each lake, which therefore precluded statistical comparisons of fish longevity among lakes.

\section{RESULTS}

\section{Growth Patterns and Longevity}

Yellow perch collected from along the Rouyn-Noranda contamination gradient demonstrated a different growth pattern as a function of age relative to those collected from along the Sudbury gradient. In Rouyn-Noranda, a quadratic function best described the relationship between fish weight or length and age (Figure 1). In Sudbury, the relationship between fish length or weight and age was best described by a cubic function. Instantaneous slopes of the lines shown in Figure 1 represent a rough approximation of instantaneous growth (length or weight) rates. In fish from the Rouyn-Noranda gradient, fish begin growing at a relatively constant (log-linear) rate at young ages, but begin to slow their growth rates as older fish begin to achieve maximum size. In Sudbury, the growth rates of young fish appear to be slow relative to Rouyn-Noranda fish. At approximately age 2 , instantaneous growth approximates

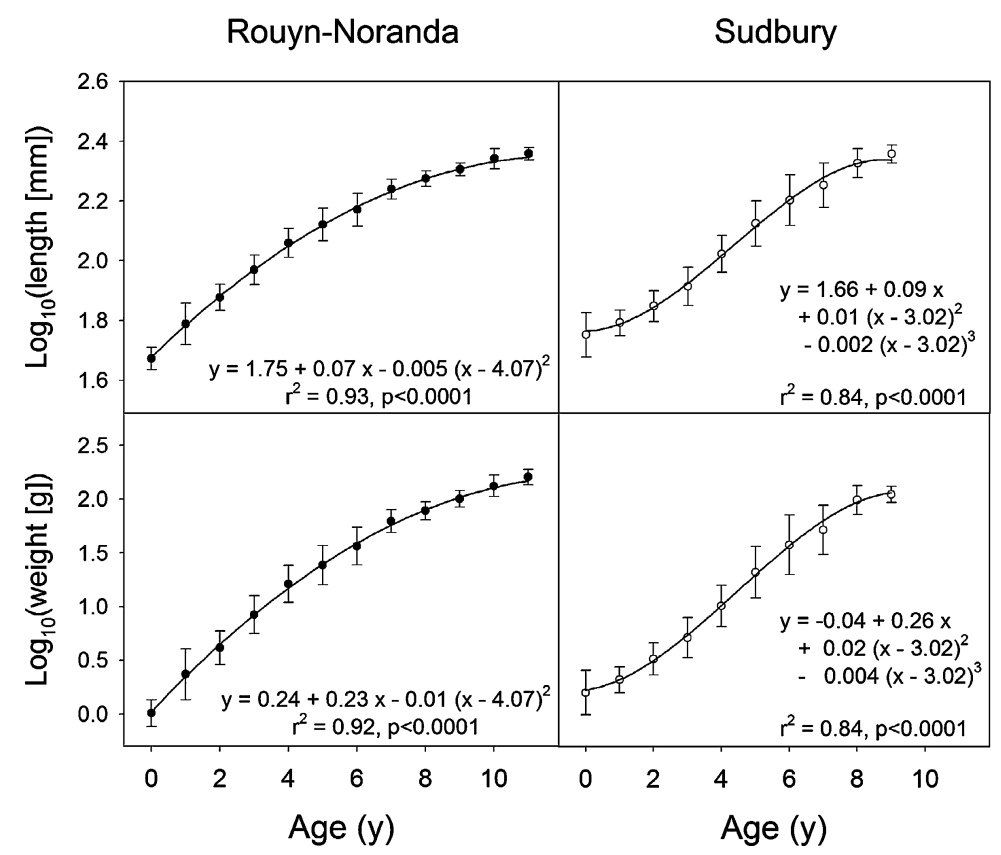

Figure 1. Length and weight at age relationships for wild yellow perch sampled from five lakes along two metal contamination gradients in Sudbury, ON ( $n=1324$, for the entire relationship) and Rouyn-Noranda, QC $(n=$ 1125), Canada. Points represent means \pm SD for each age group. Black dots represent fish from Rouyn-Noranda lakes, white dots represent fish from Sudbury lakes. 


\section{G. Pyle et al .}

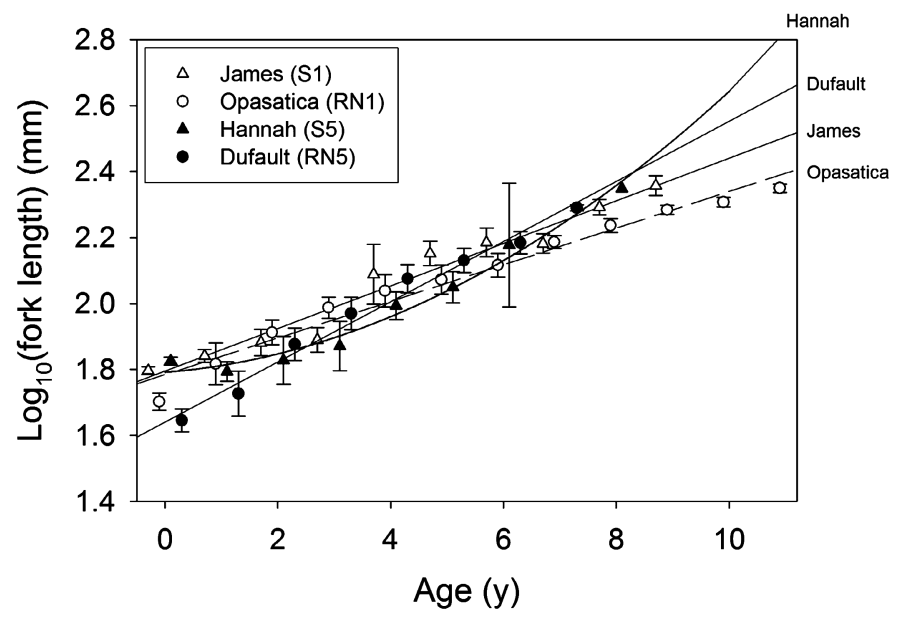

Figure 2. Length at age relationships for yellow perch sampled from the cleanest (RN1 and S1) and most metal contaminated (RN5 and S5) lakes in each of the two metal-contamination gradients studied. Points at each age class are artificially offset for the sake of clarity. Equations for each fitted line are given in the text. Triangles represent fish from Sudbury-area lakes, circles represent fish from Rouyn-Noranda lakes. White symbols represent clean (reference) lakes, whereas black symbols indicate contaminated lakes.

a log-linear pattern until fish are approximately $6 \mathrm{y}$ in age, after which the growth rate declines as fish achieve maximum size.

To understand how aqueous contamination affects growth patterns, we examined length-at-age relationships between the two least contaminated lakes (RN1 and S1) with growth patterns in fish from the two most contaminated lakes (RN5 and S5) (Figure 2). Three of the four lakes could be fitted with a linear curve (RN1, $y=1.76$ $+0.6 x, r^{2}=0.91, p<.0001 ; \mathrm{S} 1, y=1.78+0.07 x, r^{2}=0.89, p<.0001 ; \mathrm{RN} 5, y=$ $1.66+0.09 x, r^{2}=0.92, p<.0001$; where $y$ is $\log _{10}$ (fork length, $\mathrm{mm}$ ) and $x$ is age in years). However, S5 demonstrated a nonlinear relationship with age that was best fit with a polynomial function $\left(\mathrm{S} 5, y=1.69+0.07 x+0.009(x-3.12)^{2}, r^{2}=0.72\right.$, $p<.0001)$. Visual inspection of Figure 2 indicates that fish from contaminated lakes tend to grow at a faster rate than those from clean lakes. We then pooled data from all reference lakes (i.e., ranks 1 and 2 from each gradient) and contaminated lakes (i.e., ranks 4 and 5), fitted linear models to each set of data, and compared slopes to determine if this trend held. Fish from reference lakes $(y=1.74+0.07 x)$ grew at a significantly slower rate than those from contaminated lakes $(y=1.69+0.08 x)(t$ ratio $=-9.7, d . f .=1511, p<.0001)$. By back-transforming slopes, we estimate that fish from contaminated lakes grew approximately $1.016 \mathrm{~mm} / \mathrm{y}(1.013-1.019 \mathrm{~mm} / \mathrm{y}$, 95\% confidence interval) more than fish from reference lakes. This difference in estimated growth rate represents a maximum of $10 \%$ difference in growth (i.e., fork length) between fish from contaminated lakes relative to reference lakes over the life span of a wild fish (i.e., up to $11 \mathrm{y}$ in our study). 


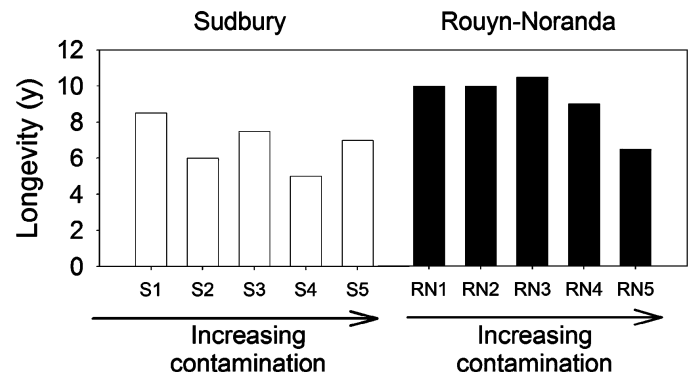

Figure 3. Longevity of wild yellow perch sampled from five lakes along each of two metal contamination gradients. In each gradient, lakes are arranged in order of increasing contamination from left to right. White bars indicate Sudbury-area lakes; black bars indicate Rouyn-Noranda lakes.

Fish from lakes comprising the Rouyn-Noranda gradient typically lived longer than those from the Sudbury gradient (Figure 3). Longevity generally decreased along each contamination gradient. In Rouyn-Noranda lakes, longevity was approximately similar in the clean and intermediate lakes (RN1-RN3). In contaminated Rouyn-Noranda lakes (RN4 and RN5), longevity decreased. Although the same basic trend of decreasing longevity with increasing contamination was also observed in Sudbury-area lakes, the relationship was less straightforward relative to longevity trends in Rouyn-Noranda lakes. Lake S1 yielded the oldest living fish in the gradient,

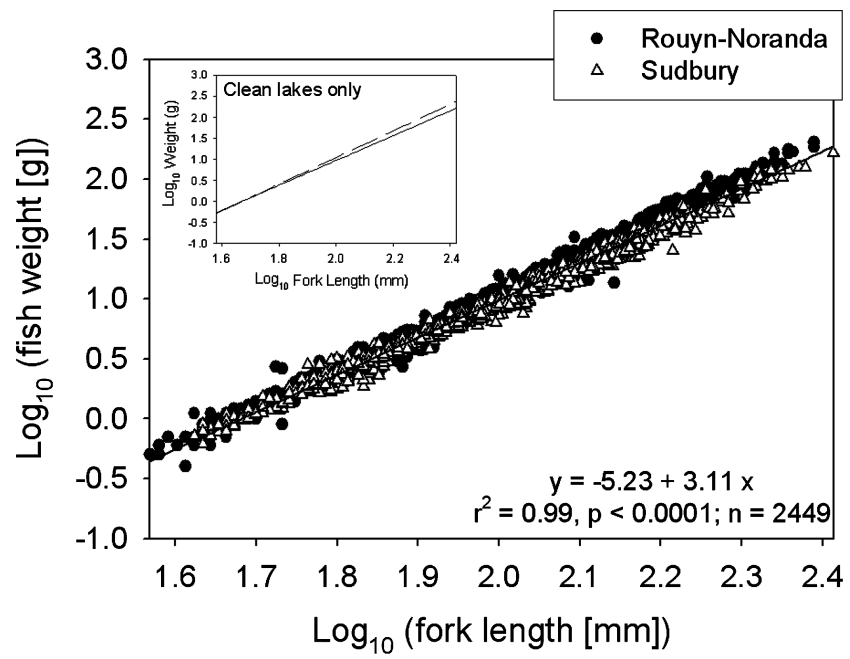

Figure 4. Log-log plot depicting the relationship between length and weight of wild yellow perch sampled from five lakes along two metal-contamination gradients. A single line was fitted to the entire dataset. Inset: Regression lines describing log-log length-weight relationships in fish collected from the two reference lakes in Rouyn-Noranda (dotted line; $n=476$ ) and two reference lakes in Sudbury (solid line; $n=514$ ). Individual data were excluded for the sake of clarity. The slopes of these two lines were significantly different $(t$ ratio $=12.35, d . f .=989, p<.0001)$. 


\section{G. Pyle et al .}

while S4 supported fish with the shortest longevity. Longevity in S3 and S5 was longer than in S2 and S4. This non-monotonic relationship may reflect variability in longevity due to natural factors.

The log-log plot of fish weight versus fish length, regardless of which gradient or season fish were collected, yielded a highly significant linear relationship $\left(r^{2}=\right.$ $0.99, p<.0001$; Figure 4 ). The pooled slope of this relationship was $3.11 \mathrm{~g} / \mathrm{mm}$ (in $\log _{10}$-transformed units). However, when data from each contamination gradient were analysed separately, fish from Rouyn-Noranda grew significantly heavier per unit length $\left(y=-5.27+3.14 x\right.$; where $y$ is $\log _{10}$ fish weight $(\mathrm{g})$ and $x$ is $\log _{10}$ fish length $(\mathrm{mm}))$ than fish from Sudbury $(y=-5.05+3.00 x)$ given that the slopes of these two relationships were significantly different $(t$ ratio $=10.88, d . f .=2448, p<$ $.0001)$. Slopes were also compared between the two regions after pooling fish from the two cleanest lakes (ranks 1 and 2) in each region (Figure 4 inset). The slope of the line characterizing the weight-length relationship in Rouyn-Noranda fish $(y=$ $\left.-5.29+3.17 x ; r^{2}=0.99, n=476, p<.0001\right)$ was significantly greater $(t$ ratio $=$ $12.35, d . f .=989, p<.0001)$ than that describing fish from Sudbury $(y=-4.94+$ $\left.2.95 x ; r^{2}=0.99, n=514, p<.0001\right)$.

\section{CONDITION}

\section{Effects of Contamination Rank, Region, and Season}

Model I was constructed from all sampled fish in the study $(n=2449)$ and provided insights into the effects of contamination rank, region, and season (Table 1).

Table 1. Main effects of contamination rank, region, and season on yellow perch condition, assuming separate slopes for each effect, and after removing all variability associated with fish length (full model $\left.r^{2}=0.994, p<.0001 ; n=2449\right)$.

\begin{tabular}{lccrc}
\hline Source & Estimate, $\beta$ & SE & tRatio & $\mathrm{p}$ \\
\hline Intercept; $a[0]$ & -5.18368 & 0.01174 & -441.65 & $<.0001$ \\
$\log _{10}\left(L_{i}\right)(\mathrm{mm}) ; b$ & 3.08907 & 0.00589 & 524.40 & $<.0001$ \\
Effect of Rank; $a[k] * \log _{10}\left(L_{i}\right)$ & & & \\
$\quad$ Rank 1 & -0.00833 & 0.01271 & -0.66 & .51 \\
Rank 2 & 0.05166 & 0.01204 & 4.29 & $<.0001$ \\
Rank 3 & 0.02392 & 0.01038 & 2.31 & .02 \\
Rank 4 & 0.00669 & 0.01203 & 0.56 & .58 \\
$\quad$ Rank 5 & -0.07394 & 0.01162 & -6.36 & $<.0001$ \\
Effect of Region; $a[r] * \log _{10}\left(L_{i}\right)$ & & & \\
$\quad$ Rouyn-Noranda & 0.08082 & 0.00589 & 13.72 & $<.0001$ \\
$\quad$ Sudbury & -0.08082 & 0.00589 & -13.72 & $<.0001$ \\
Effect of Season; $a[s] * \log _{10}\left(L_{i}\right)$ & & & \\
$\quad$ Spring & -0.02542 & 0.00589 & -4.32 & $<.0001$ \\
Summer & 0.02542 & 0.00589 & 4.32 & $<.0001$ \\
\hline
\end{tabular}

Estimates correspond with the logarithmic geometric mean deviation of $K$ from unity within a comparative group (parameter class), and are representative of a factor's effect on fish condition. 


\section{Metal Effects on Growth and Condition in Wild Yellow Perch}

Table 2. Main effects and interactions of contamination rank and season on Sudbury yellow perch condition, assuming separate slopes for each effect, and after removing all variability associated with fish length (full model $r^{2}=0.993, p<.0001 ; n=1324$ ).

\begin{tabular}{lcccc}
\hline Source & Estimate, $\beta$ & $\mathrm{SE}$ & $t$ Ratio & $\mathrm{p}$ \\
\hline Intercept; $\log _{10}(a[0])$ & -5.05338 & 0.01756 & -287.76 & $<.0001$ \\
$\log _{10}\left(L_{i}\right)(\mathrm{mm}) ; b$ & 3.00825 & 0.00891 & 337.78 & $<.0001$ \\
Effect of Rank; $\log _{10}(a[k]) * \log _{10}\left(L_{i}\right)$ & & & \\
$\quad$ Rank 1 & 0.01066 & 0.01919 & 0.56 & .58 \\
Rank 2 & 0.08497 & 0.01809 & 4.70 & $<.0001$ \\
Rank 3 & -0.03719 & 0.01446 & -2.57 & .01 \\
Rank 4 & -0.02391 & 0.01902 & -1.26 & .21 \\
Rank 5 & -0.03453 & 0.01788 & -1.93 & .05 \\
Effect of Season; $\log _{10}(a[s]) * \log _{10}\left(L_{i}\right)$ & & & \\
Spring & -0.06319 & 0.00891 & -7.10 & $<.0001$ \\
Summer & 0.06319 & 0.00891 & 7.10 & $<.0001$ \\
Season $\times$ Rank Interaction; $\log _{10}(a[s]) * \log 10$ & $(a[k]) * 109$ \\
Spring & & & & \\
Rank 1 & -0.07788 & 0.01919 & -4.06 & $<.0001$ \\
Rank 2 & 0.07181 & 0.01809 & 3.97 & $<.0001$ \\
Rank 3 & 0.09356 & 0.01446 & 6.47 & $<.0001$ \\
Rank 4 & 0.00204 & 0.01902 & 0.11 & .91 \\
Rank 5 & -0.08952 & 0.01788 & -5.01 & $<.0001$ \\
Summer & & & \\
Rank 1 & 0.07788 & 0.01919 & 4.06 & $<.0001$ \\
Rank 2 & -0.07181 & 0.01809 & -3.97 & $<.0001$ \\
Rank 3 & -0.09356 & 0.01446 & -6.47 & $<.0001$ \\
Rank 4 & -0.00204 & 0.01902 & -0.11 & .91 \\
Rank 5 & 0.08952 & 0.01788 & 5.01 & $<.0001$ \\
\hline
\end{tabular}

Estimates correspond with the logarithmic geometric mean deviation of $K$ from unity within a comparative group (parameter class), and are representative of a factor's effect on fish condition.

Condition of fish from rank $1(p=0.51)$ and rank $4(p=0.58)$ lakes were not significantly different from mean condition. Fish condition generally increased beyond mean condition in lakes comprising ranks 2 and 3. However, fish occupying rank $5(\beta=-0.07394, p<.0001)$ lakes were of significantly lower condition than the mean of the sample. Fish from Sudbury-area lakes had significantly lower condition than those from Rouyn-Noranda $(p<.0001)$. Moreover, condition was significantly lower in the spring than in the summer $(p<.0001)$. The slope term for the entire model $(b)$, which is effectively the scaling coefficient, was $3.08 \mathrm{~g} / \mathrm{mm}$ (logged units; $p<.0001$ ), which corresponds closely to the slope of the curve reported in Figure 4.

Effects of rank and season were studied by examining fish collected from Sudbury (Table 2) or Rouyn-Noranda (Table 3) lakes separately. This analysis allowed for the construction of separate models for fish collected from each contamination gradient, which in turn allowed for examination of interacting terms. Fish from Sudbury-area lakes (Table 2) demonstrated relatively high condition in the lower-ranked lakes 


\section{G. Pyle et al .}

Table 3. Main effects of contamination rank and season on Rouyn-Noranda yellow perch condition, assuming separate slopes for each effect, and after removing all variability associated with fish length (full model $\left.r^{2}=.995, p<.0001 ; n=1125\right)$. Estimates correspond with the logarithmic geometric mean deviation of $K$ from unity within a comparative group (parameter class), and are representative of a factor's effect on fish condition.

\begin{tabular}{lrrrl}
\hline Source & Estimate, $\beta$ & SE & $t$ Ratio & $p$ \\
\hline Intercept; $\log _{10}(a[0])$ & -5.31399 & 0.01511 & -351.58 & $<.0001$ \\
$\log _{10}\left(L_{i}\right)(\mathrm{mm}) ; b$ & 3.16989 & 0.00744 & 425.84 & $<.0001$ \\
Effect of Rank; $\log _{10}(a[k]) * \log _{10}\left(L_{i}\right)$ & -0.02732 & 0.01609 & -1.70 & .09 \\
$\quad$ Rank 1 & 0.01836 & 0.01538 & 1.19 & .23 \\
Rank 2 & 0.08503 & 0.01484 & 5.73 & $<.0001$ \\
Rank 3 & 0.03729 & 0.01382 & 2.70 & .007 \\
Rank 4 & -0.11335 & 0.01419 & -7.99 & $<.0001$ \\
Rank 5 & 0.01235 & 0.00744 & & \\
Effect of Season; $\log _{10}(a[s]) * \log _{10}\left(L_{i}\right)$ & 0.00744 & -1.66 & .10 \\
Spring & -0.01235 & & & .10 \\
Summer & $(a[s]) * \log _{10}(a[k]) * 109$ & \\
Season $\times$ Rank Interaction; $\log _{10}\left(L_{i}\right)$ & & \\
Spring & & & & \\
Rank 1 & 0.00641 & 0.01609 & 0.40 & .69 \\
Rank 2 & -0.05751 & 0.01538 & -3.74 & .0002 \\
Rank 3 & 0.01495 & 0.01484 & 1.01 & .31 \\
Rank 4 & 0.10949 & 0.01382 & 7.92 & $<.0001$ \\
Rank 5 & -0.07334 & 0.01419 & -5.17 & $<.0001$ \\
Summer & & & & \\
Rank 1 & -0.00641 & 0.01609 & -0.40 & .69 \\
Rank 2 & 0.05751 & 0.01538 & 3.74 & .0002 \\
Rank 3 & -0.01495 & 0.01484 & -1.01 & .31 \\
Rank 4 & -0.10949 & 0.01382 & -7.92 & $<.0001$ \\
Rank 5 & 0.07334 & 0.01419 & 5.17 & $<.0001$ \\
\hline
\end{tabular}

(i.e., S1 and S2, although condition of S1 fish was not significantly different from mean condition of Sudbury-area fish; $p=.58$ ) relative to those from contaminated lakes (i.e., S3-S5, although condition of fish from S4 was not significantly different from mean condition for all Sudbury fish; $p=.21$ ). In Sudbury, fish condition was significantly lower in the spring than in the summer $(p<.0001)$. However, there was a significant interaction between rank and season among Sudbury fish. Fish from S1 and S5 demonstrated significantly lower condition in the spring relative to the summer $(p<.0001)$. On the other hand, fish from S2 and S3 showed higher condition in the spring relative to the summer $(p<.0001)$, whereas the condition of fish from $\mathrm{S} 4$ remained relatively unaffected by season $(p=.91)$. The slope term $(b)$ for the Sudbury model was $3.01 \mathrm{~g} / \mathrm{mm}$ (logged units; $p<.0001)$, which corroborates 


\section{Metal Effects on Growth and Condition in Wild Yellow Perch}

the slope established for Sudbury fish when data from Figure 4 were analyzed by separating regions $(3.00 \mathrm{~g} / \mathrm{mm}$ in logged units).

Condition patterns in Rouyn-Noranda fish were somewhat different than those for Sudbury fish (Table 3). Condition of fish from RN1 and RN2 was not significantly different than mean condition for all Rouyn-Noranda fish $(p>.05)$. However, fish from RN3 and RN4 had significantly higher condition, and those from RN5 had significantly lower condition than the mean. Contrary to seasonal influences on Sudbury fish, Rouyn-Noranda fish demonstrated significantly higher condition in the spring than the summer $(p<.0001)$. However, similar to observations on Sudbury fish, there was a significant interaction between rank and season in Rouyn-Noranda fish. Fish from RN2 and RN5 had significantly lower condition in the spring than in the summer $(p<.0003)$, whereas those from RN4 had higher condition in the spring than the summer $(p<.0001)$. Condition of fish from RN1 and RN3 did not vary seasonally $(p>.30)$. Rouyn-Noranda fish demonstrated a similar slope parameter $(b=3.17 \mathrm{~mm} / \mathrm{g})$ relative to the $3.14 \mathrm{~mm} / \mathrm{g}$ established for Rouyn-Noranda fish above (Figure 4) and higher than that demonstrated by Sudbury fish $(b=3.01$ $\mathrm{mm} / \mathrm{g}$; Table 2).

\section{Effects of Tissue Metals on Fish Condition}

Models were constructed to examine the influence of tissue metals on fish condition. In Sudbury-area lakes, liver $\mathrm{Zn}$ was related to lower condition $(p=.01$; Table 4). Surprisingly, the three metals of greatest concern in Sudbury-area lakes, Cd, Cu and $\mathrm{Ni}$, were not related to fish condition. However, in Rouyn-Noranda fish metals did have an influence on condition (Table 5). Of the Rouyn-Noranda fish used in the tissue-metal analysis $(n=167)$, marginally lower condition was observed in the spring than the summer $(p=.05)$. Kidney Ni was related to lower fish condition in Rouyn-Noranda fish, overall ( $b=-0.10881 ; p=.02)$, regardless of season. However, because of a significant interaction between kidney $\mathrm{Ni}$ and season on fish condition, kidney Ni concentrations were associated with higher condition in the spring than the summer in Rouyn-Noranda lakes $(p=.0007)$. Although there was no main effect of kidney $\mathrm{Zn}$ on fish condition $(p=.21)$, kidney $\mathrm{Zn}$ was related to lower fish condition in the spring than the summer $(p=.007)$.

Table 4. Effects of tissue metal concentration on Sudbury yellow perch condition $\left(r^{2}=0.992, p<0.0001, n=137\right)$ after removing variability of fish length. Estimates correspond with the logarithmic geometric mean deviation of $K$ from unity within a comparative group (parameter class), and are representative of a factor's effect on fish condition.

\begin{tabular}{lcccc}
\hline Source & Estimate, $\beta$ & SE & $t$ Ratio & $p$ \\
\hline Intercept; $a[0]$ & -5.02189 & 0.08986 & -55.89 & $<.0001$ \\
$\log _{10}\left(L_{i}\right)(\mathrm{mm}) ; b$ & 3.01454 & 0.02508 & 120.18 & $<.0001$ \\
Effect of Tissue Metal Concentration; $m\left(X_{i}\right) * \log _{10}\left(L_{i}\right)$ & & \\
$\quad$ Liver Zn & -0.43242 & 0.17239 & -2.51 & .01 \\
\hline
\end{tabular}




\section{G. Pyle et al .}

Table 5. Seasonal effects of tissue metal concentration on Rouyn-Noranda yellow perch condition $\left(r^{2}=0.994, p<.0001, n=167\right)$ after removing variability of fish length. Estimates correspond with the logarithmic geometric mean deviation of $K$ from unity within a comparative group (parameter class), and are representative of a factor's effect on fish condition.

\begin{tabular}{lcccc}
\hline Source & Estimate, $\beta$ & SE & $t$ Ratio & $p$ \\
\hline Intercept; $a[0]$ & -4.57457 & 0.09795 & -46.70 & $<.0001$ \\
$\log _{10}\left(L_{i}\right)(\mathrm{mm}) ; b$ & 2.99882 & 0.03290 & 91.15 & $<.0001$ \\
Effect of Season; $\log _{10}(a[s]) * \log _{10}\left(L_{i}\right)$ & & & \\
$\quad-0.06732$ & 0.03381 & -1.99 & .05 \\
$\quad$ Spring & 0.06732 & 0.03381 & 1.99 & .05 \\
$\quad$ Summer & & & \\
Effect of Tissue Metal Concentration; $m\left(X_{i}\right) * \log _{10}\left(L_{i}\right)$ & & \\
Kidney & -0.10881 & 0.04425 & -2.46 & .02 \\
$\quad$ Ni & -0.22441 & 0.17820 & -1.26 & .21 \\
Zn & & & & \\
Gut contents & 0.14234 & 0.06684 & 2.13 & .03 \\
$\quad$ Cu & -0.25496 & 0.11387 & -2.24 & .03 \\
Zn & & & \\
Liver & 0.11527 & 0.03956 & 2.91 & .004 \\
$\quad$ Ni & & & \\
Season $\times$ Tissue Metal Concentration Interaction; $\log _{10}(a[s]) * m\left(X_{i}\right) * \log _{10}\left(L_{i}\right)$ & \\
Kidney Ni & 0.15727 & 0.04547 & 3.46 & .0007 \\
$\quad$ Spring & -0.15727 & 0.04547 & -3.46 & .0007 \\
Summer & & & \\
Kidney Zn & -0.38331 & 0.14026 & -2.73 & .007 \\
$\quad$ Spring & 0.38331 & 0.14026 & 2.73 & .007 \\
$\quad$ Summer & & & \\
\hline
\end{tabular}

\section{DISCUSSION}

This study revealed the complex relationships of season, region, degree of environmental metal contamination $(\mathrm{Cd}, \mathrm{Cu}, \mathrm{Ni}, \mathrm{Se}$, and $\mathrm{Zn})$, and tissue metal loads on wild yellow perch condition. We sampled fish from five lakes along each of two distinct metal contamination gradients: a major Ontario metal mining region with long-standing, wide-spread, and well-documented contamination (Sudbury), and another in a major copper smelting and mining region in Québec (Rouyn-Noranda). Water quality in lakes comprising each gradient reflected the specific nature of the contamination source (Couture et al. 2008a). Briefly, Sudbury-area lakes were dominated by $\mathrm{Cd}, \mathrm{Cu}$, and $\mathrm{Ni}$ contamination, whereas lakes comprising the RouynNoranda gradient were dominated by $\mathrm{Cd}$, $\mathrm{Cu}$, and $\mathrm{Zn}$.

Growth patterns in fish collected from the two gradients were different (Figure 1 and inset to Figure 4). Differences in growth patterns could reflect differences in food availability after over-wintering resulting in compensatory growth (Hayward and Wang 2001), differences in annual energetic allocation (Henderson et al. 2000), or genetic differences between populations from two distinct watersheds and metal 


\section{Metal Effects on Growth and Condition in Wild Yellow Perch}

contamination gradients (Belfiore and Anderson 2001). Rouyn-Noranda fish appeared to begin rapid growth immediately, whereas Sudbury fish grew slowly during their first few years when growth rates appeared to increase at approximately age 3 (Figure 1). In both gradients, growth rates began to decline as fish approached their maximum size. Moreover, fish from reference lakes in the Rouyn-Noranda gradient tended to be heavier per unit length than fish from reference lakes in the Sudbury gradient (Figure 4 inset). This result is interesting because it highlights differences in fish growth patterns between the two gradients independent of metal contamination.

Regional differences in growth patterns may be attributable to several factors that may or may not have anything to do with metal contamination (Dutta 1994). Along the metal-contamination gradient, differences in growth patterns may reflect indirect consequences of elevated environmental metals, such as differences in food abundance and availability resulting in differences in the energy invested in foraging (Sherwood et al. 2000), habitat quality, or direct consequences such as the energetic demands associated with metal detoxification and homeostatic maintenance (Marchand et al. 2004). Given that length-weight relationships were different in reference lakes in the two regions (Figure 4 inset), and that length-at-age growth patterns were strikingly different between the two regions, we speculate that growth pattern differences result from genetic differences between the two populations. However, we cannot rule out the possibility of other regional-specific factors that may influence growth patterns.

Fish inhabiting contaminated lakes tended to grow faster (Figure 2) and die younger (Figure 3) than fish inhabiting reference lakes. Previous work has demonstrated that yellow perch undergo one or two ontogenetic diet shifts, from planktivory to benthivory and eventually to piscivory (Sherwood et al. 2002a; Sherwood et al. 2002b). The benefit to a larger fish shifting to a larger diet is energetic cost savings through efficient foraging by selecting prey yielding high energetic payoff without excessive energy expenditure. Sherwood et al. (2002b) reported that metalcontaminated lakes in the Rouyn-Noranda region had impoverished invertebrate species diversity, which effectively limited yellow perch diet. The result of this impoverished diversity of prey organisms resulted in an energetic "bottleneck," where large yellow perch could not switch their diet from benthivory to piscivory. Moreover, the same authors reported that older yellow perch inhabiting contaminated lakes converted their food to usable energy less efficiently than fish inhabiting lakes where the final ontogenetic diet shift to piscivory was possible. Rennie et al. (2005) demonstrated that activity costs associated with foraging are more important than food intake to explain variability in growth rates, where active fish grow more slowly than less active fish.

Taking these results together, we should expect to see reduced growth per unit age in yellow perch inhabiting metal-contaminated systems owing to impoverished prey community structure, an inability of large yellow perch to shift to piscivory, increased energy allocation to active foraging, and therefore, slower growth rates. However, data reported in the current study demonstrate a higher growth rate among yellow perch from contaminated environments relative to those from reference lakes.

An important mechanism of metal intoxication in freshwater fishes is ionoregulatory dysfunction (Laurén and McDonald 1985; McDonald et al. 1989; Kolok et al. 


\section{G. Pyle et al .}

2002). These effects can occur at environmentally relevant concentrations (McDonald et al. 1989; Farag et al. 1994; Grippo and Dunson 1996). Metal-induced epithelial damage, especially at the gill, results in ion loss in freshwater fishes-particularly, $\mathrm{Na}^{+}$and $\mathrm{Ca}^{2+}$. These ion losses could increase tissue water content in metal-exposed fishes, which could lead to overestimates of fish condition (Heath 1984). Fish can compensate for metal-induced ionoregulatory dysfunction by increasing their food intake. For example, rainbow trout (Oncorhynchus mykiss) fed a satiation diet demonstrated increased appetites and increased growth in acid-exposed animals (which is also known to induce ionoregulatory disturbances similar to those observed in metalexposed animals) (Dockray et al. 1996). Therefore, fish probably overcome ionoregulatory disturbances in metal-contaminated environments by increasing their food consumption, which could ultimately lead to increased growth. Our data appear to corroborate this idea.

We have previously reported that highly contaminated lakes in the Sudbury-area generally have a reduced number of fish species that predate upon and (or) compete with yellow perch (Pyle et al. 2005). In Hannah Lake (S5), for example, only one other fish species, the Iowa darter (Etheostoma exile), was captured along with yellow perch in 2002, which suggests that competition was low and predation pressures absent for Hannah Lake yellow perch. The same may be true for contaminated lakes in the Rouyn-Noranda region.

Our observation of elevated growth rates in yellow perch inhabiting contaminated lakes relative to clean lakes probably resulted from elevated feeding activity allowed by lower competition or predation pressure (Bertolo and Magnan 2005). If the contaminated lakes we studied had greater fish species diversity, we would expect decreased food availability through interspecific competition. Increased predation pressure would also increase activity as yellow perch attempt to locate food while simultaneously avoiding predation (Kaufman et al. 2006). Consequently, it may be that the differential growth patterns observed in wild yellow perch in this study are an indirect consequence of metal contamination (Fleeger et al. 2003). Reduced species diversity in contaminated lakes means that foraging yellow perch consume high quantities of a limited number of prey species, but without opposing pressures associated with competition and predation. This kind of foraging scenario could ultimately lead to higher growth rates in fish from contaminated lakes, and offers a plausible explanation for our observations.

However, these elevated growth rates in contaminated fish come at a cost. Fish inhabiting metal-contaminated lakes generally had lower longevity than fish from cleaner lakes (Figure 3). In a companion article, we present evidence suggesting that this reduced longevity may be due to increased oxidative damage of the aerobic machinery induced by metals (Couture et al. 2008b).

Our sampling design allowed us to develop integrated least squares models to explore the single and combined influences of region, contamination rank, season, and tissue metal concentrations on fish condition. Fish from contaminated, rank 5 lakes were generally of lower condition than those from cleaner lakes. Fish condition was higher in the summer than the spring, and fish from Rouyn-Noranda were of higher condition than those from Sudbury. These results are consistent with previous studies that have demonstrated lower condition in fish from metal-contaminated sites relative to reference sites (references provided earlier). As yellow perch inhabiting 


\section{Metal Effects on Growth and Condition in Wild Yellow Perch}

contaminated lakes age, they tend to grow proportionately more in length than in weight, yielding a general decrease in condition. This is also consistent with our interpretation (earlier) of data presented in Figure 2 because those data clearly reflect higher linear growth rate in fish from contaminated lakes than in reference lakes.

Our fish condition results are also consistent with previous studies demonstrating that condition is typically higher in fish in the summer than in the spring (Audet and Couture 2003). In northeastern Ontario and northwestern Québec (i.e., the regions in which fish from this study were sampled), over-wintering stress is high and food availability is low (Audet and Couture 2003). Therefore, lower fish condition in the spring is likely a reflection of over-wintering stress associated with inhabiting Boreal Shield lakes and recent spawning activity in early spring. By summer, fish from these lakes have had a full season in which to forage and grow. Consequently, fish in our study generally have higher condition in the summer than in the spring.

These general patterns did not always hold when analyses were conducted on fish from individual gradients. In both Sudbury and Rouyn-Noranda lakes, fish condition decreased with increasing environmental contamination (Tables 2 and 3), which corroborates similar trends throughout the entire pooled dataset. Seasonal effects on fish condition, however, showed opposite trends between the two environmental gradients. Fish from Sudbury-area lakes showed lower condition in the spring than in summer, whereas Rouyn-Noranda fish had higher condition in the spring than in the summer. This difference in seasonal variability was even more pronounced when seasonal effects were examined in individual lakes of each gradient. In some cases, fish from clean lakes showed lower condition in the spring than the summer, whereas in other cases the opposite was true. The same was observed in contaminated lakes. Therefore, it is difficult to reconcile lake-specific seasonal effects on fish condition when different trends are evident in fish from lakes occupying similar positions along each of the two contamination gradients.

This result emphasizes the importance of understanding the high degree of natural variability associated with establishing lake-specific fish condition. Because fish condition integrates a number of influential biotic (e.g., genetic population differences, food availability, competition, predation pressure) and abiotic (e.g., temperature, climate patterns, habitat quality) factors, long-term and wide-scale environmental processes are essential for establishing broad trends in fish condition (Pyle et al. 2005). Short-term, lake-specific factors can be influential on instantaneous fish condition. However, the high degree of natural variability in snapshot-type condition measurements means that small, short-term, lake-specific influences on condition may lead to confusing and sometimes contradictory results and could mask more important long-term trends evident only when sufficient data are available.

Dietary and tissue $\mathrm{Zn}$ concentrations demonstrated a significant negative relationship to fish condition in both contamination gradients. However, Zn concentrations measured in these tissues were insufficient to suggest that $\mathrm{Zn}$ itself was having an influence on condition (Couture et al. 2008a). Cadmium, $\mathrm{Cu}$, and $\mathrm{Zn}$ concentrations demonstrate a high degree of covariation in gut contents and fish tissue samples. Of these three covariate metals, $\mathrm{Cd}$ and $\mathrm{Cu}$ show most variability in gut contents and tissue measurements, whereas $\mathrm{Zn}$ is relatively stable, probably because of the slower clearance time for Zn relative to Cd or Cu (Gill et al. 1992; Chowdhury et al. 2003). 


\section{G. Pyle et al .}

As described earlier, it may be that long-term metal (specifically, Zn) accumulation trends account for more fish condition variability than highly variable short-term metal accumulation trends (specifically, $\mathrm{Cd}$ and $\mathrm{Cu}$ ). Given that tissue $\mathrm{Zn}$ concentrations are strongly correlated to $\mathrm{Cd}$ and $\mathrm{Cu}$ concentrations and vary little over time in fish tissues and diet, and that fish condition is likely an integrated reflection of long-term processes, it may be that other, more hazardous metals, such as $\mathrm{Cd}$ and $\mathrm{Cu}$, influence condition more than $\mathrm{Zn}$, but that $\mathrm{Zn}$ was reflected in the analysis because of its closer association to long-term changes in fish condition.

Copper and Ni are the two metals of most concern around Sudbury-area lakes. However, neither of these metals appeared to have any influence on fish condition in these lakes. Fish from Sudbury-area lakes appear to better regulate tissue $\mathrm{Cu}$ and $\mathrm{Ni}$ concentrations relative to those from Rouyn-Noranda lakes (Couture et al. 2008a). In Rouyn-Noranda, however, kidney Ni was associated with lower fish condition (Table 5). Although environmental Ni concentrations were relatively low in Rouyn-Noranda lakes, we noted a significant increase in tissue Ni concentrations in fish collected from Rouyn-Noranda lakes in the spring (Couture et al. 2008a). Actively feeding fish consuming Ni-contaminated food would demonstrate an increase in condition (from the feeding activity) and elevated tissue Ni concentrations, as nutrients and $\mathrm{Ni}$ are transported to the liver and kidney from the gut for processing and elimination.

In conclusion, this study demonstrated that fish from two distinct metal contamination gradients had distinctive, gradient-specific growth patterns. Fish from contaminated lakes generally grew faster and died younger than fish from reference lakes. Fish condition was higher in Rouyn-Noranda fish than Sudbury fish, generally decreased with increasing contamination, and was lower in the spring than in the summer. These trends are relatively well established and corroborate several other studies noting similar trends. However, at the level of individual lakes in each contamination gradient, high variability in condition made it difficult to establish seasonal trends. Fish condition integrates lake-specific long-term and wide-scale biotic and abiotic environmental factors. Consequently, when attempting to establish basic relationships between fish condition and environmental factors, it is imperative to establish intra-lake condition variability to minimize the probability of drawing false conclusions on fish condition. Finally, although our analysis suggested that tissue Zn accumulation had a significant influence on fish condition, this may be a reflection of relatively low temporal $\mathrm{Zn}$ variability, which itself correlates with long-term trends. It is much more likely that fish condition was influenced by $\mathrm{Zn}$ covariates, such as Cd or $\mathrm{Cu}$. However, both $\mathrm{Cd}$ and $\mathrm{Cu}$ demonstrate a higher degree of temporal variability and tissue concentrations of these metals likely reflect short-term processes, such as recent feeding activity and growth.

\section{AGKNOWLEDGEMENTS}

This research was supported by a grant from the Metals in the Environment Research Network to PC and GP as well as by NSERC Discovery funding to PC. Renée Stewart, Joelle Violette, and Mehran Bakhtiari provided assistance with field work in Sudbury. Useful review comments were provided by four anonymous referees. 


\section{Metal Effects on Growth and Condition in Wild Yellow Perch}

\section{REFERENCES}

Audet D and Couture P. 2003. Seasonal variations in tissue metabolic capacities of yellow perch (Perca flavescens) from clean and metal-contaminated environments. Can J Fish Aquat Sci 60:269-78

Belfiore NM and Anderson SL. 2001. Effects of contaminants on genetic patterns in aquatic organisms: A review. Mutat Res 489:97-122

Bennett PM and Janz DM. 2007. Bioenergetics and growth of young-of the-year northern pike (Esox lucius) and burbot (Lota lota) exposed to metal mining effluent. Ecotoxicol Environ Saf 68:1-12

Bertolo A and Magnan P. 2005. The relationship between piscivory and growth of white sucker (Catostomus commersoni) and yellow perch (Perca flavescens) in headwater lakes of the Canadian Shield. Can J Fish Aquat Sci 62:2706-15

Bervoets L and Blust R. 2003. Metal concentrations in water, sediment and gudgeon (Gobio gobio) from a pollution gradient. Environ Pollut 126:9-19

Chowdhury MJ, Grosell M, McDonald DG, et al. 2003. Plasma clearance of cadmium and zinc in non-acclimated and metal-acclimated trout. Aquat Toxicol 64:259-75

Couillard Y, Campbell PGC, and Tessier A. 1993. Response of metallothionein concentrations in a freshwater bivalve (Anodonta grandis) along an environmental cadmium gradient. Limnol Oceanogr 38:299-313

Couture P and Kumar PR. 2003. Impairment of metabolic capacities in copper and cadmium contaminated wild yellow perch (Perca flavescens). Aquat Toxicol 64:107-20

Couture P and Rajotte JW. 2003. Morphometric and metabolic indicators of metal stress in wild yellow perch (Perca flavescens) from Sudbury, Ontario: A review. J Environ Monit 5:216-21

Couture P, Busby P, Rajotte J, et al. 2008a. Seasonal and regional variations of metal contamination and condition indicators in yellow perch (Perca flavescens) along two polymetallic gradients. I. Factors influencing tissue metal concentrations. Hum Ecol Risk Asses (this issue)

Couture P, Rajotte J, and Pyle G. 2008b. Seasonal and regional variations of metal contamination and condition indicators in yellow perch (Perca flavescens) along two polymetallic gradients. III. Energetic and physiological indicators. Hum Ecol Risk Asses (this issue)

Dockray JJ, Reid SD, and Wood CM. 1996. Effects of elevated summer temperatures and reduced $\mathrm{pH}$ on metabolism and growth of juvenile rainbow trout (Oncorhynchus mykiss) on unlimited ration. Can J Fish Aquat Sci 53:2752-63

Dutta H. 1994. Growth in fishes. Gerontology 40:97-112

Eastwood S and Couture P. 2002. Seasonal variations in condition and liver metal concentrations of yellow perch (Perca flavescens) from a metal-contaminated environment. Aquat Toxicol 58:43-56

Eaton JG, Swenson WA, McCormick JH, et al. 1992. A field and laboratory investigation of acid effects on largemouth bass, rock bass, black crappie, and yellow perch. Trans Am Fish Soc 121:644-58

Farag AM, Boese CJ, Woodward DF, et al. 1994. Physiological changes and tissue metal accumulation in rainbow trout exposed to foodborne and waterborne metals. Environ Toxicol Chem 13:2021-9

Farkas A, Salanki J, and Specziar A. 2003. Age- and size-specific patterns of heavy metals in the organs of freshwater fish Abramis brama L. populating a low-contaminated site. Wat Res 37:959-64

Fleeger JW, Carman KR, and Nisbet RM. 2003. Indirect effects of contaminants in aquatic ecosystems. Sci Tot Environ 317:207-33 


\section{G. Pyle et al .}

Gill TS, Bianchi CP, and Epple A. 1992. Trace metal (Cu and Zn) adaptation of organ systems of the American eel, Anguilla rostrata, to external concentrations of cadmium. Comparative Biochemistry and Physiology Part C: Toxicology \& Pharmacology 102:361-71

Grippo RS and Dunson WA. 1996. The body ion loss biomarker 1. Interactions between trace metals and low $\mathrm{pH}$ in reconstituted coal mine-polluted water. Environ Toxicol Chem 15:1955-63

Hayward RS and Wang N. 2001. Failure to induce over-compensation of growth in maturing yellow perch. J Fish Biol 59:126-40

Heath AG. 1984. Changes in tissue adenylates and water content of bluegill, Lepomis macrochirus, exposed to copper. J Fish Biol 24:299-309

Henderson BA, Trivedi T, and Collins N. 2000. Annual cycle of energy allocation to growth and reproduction of yellow perch. J Fish Biol 57:122-33

Kaufman SD, Gunn JM, Morgan GE, et al. 2006. Muscle enzymes reveal walleye (Sander vitreus) are less active when larger prey (cisco, Coregonus artedi) are present. Can J Fish Aquat Sci 63:970-9

Keller W, Gunn JM, and Yan ND. 1992. Evidence of biological recovery in acid-stressed lakes near Sudbury, Canada. Environ Pollut 78:79-85

Kolok AS, Hartman MM, and Sershan J. 2002. The physiology of copper tolerance in fathead minnows: Insight from an intraspecific, correlative analysis. Environ Toxicol Chem 21:1730-5

Laflamme J-S, Couillard Y, Campbell PGC, et al. 2000. Interrenal metallothionein and cortisol secretion in relation to $\mathrm{Cd}, \mathrm{Cu}$, and $\mathrm{Zn}$ exposure in yellow perch, Perca flavescens, from Abitibi lakes. Can J Fish Aquat Sci 57:1692-700

Laurén DJ and McDonald DG. 1985. Effects of copper on branchial ionoregulation in the rainbow trout, Salmo gairdneri Richardson. J Comp Physiol (B) 155:635-44

Le Cren ED. 1951. The length-weight relationship and seasonal cycle in gonad weight and condition in the perch (Perca fluviatilis). J Anim Ecol 20:201-19

Leis AL and Fox MG. 1994. Effect of mine tailings on the in situ survival of walleye (Stizostedion vitreum) eggs in a northern Ontario river. Ecosci 1:215-22

Levesque HM, Moon TW, Campbell PG, et al. 2002. Seasonal variation in carbohydrate and lipid metabolism of yellow perch (Perca flavescens) chronically exposed to metals in the field. Aquat Toxicol 60:257-67

Levesque HM, Dorval J, Hontela A, et al. 2003. Hormonal, morphological, and physiological responses of yellow perch (Perca flavescens) to chronic environmental metal exposures. J Toxicol Environ Health 66:657-76

Lohner TW, Reash RJ, Willet VE, et al. 2001. Assessment of tolerant sunfish populations (Lepomis sp.) inhabiting selenium-laden coal ash effluents. 3. Serum chemistry and fish health indicators. Ecotoxicol Environ Saf 50:225-32

Marchand J, Quiniou L, Riso R, et al. 2004. Physiological cost of tolerance to toxicants in the European flounder Platichthys flesus, along the French Atlantic Coast. Aquat Toxicol 70:327-43

McDonald DG, Reader JP, and Dalziel TRK. 1989. The combined effects of pH and trace metals on fish ionoregulation. In: Morris R, Taylor EW, Brown DJA, and Brown JA (eds), Acid Toxicity and Aquatic Animals, pp 221-41. Cambridge University Press, Cambridge, UK

Patterson KR. 1992. An improved method for studying the condition of fish, with an example using Pacific sardine Sardinops sagax (Jenyns). J Fish Biol 40:821-31

Pyle GG, Rajotte JW, and Couture P. 2005. Effects of industrial metals on wild fish populations along a metal contamination gradient. Ecotoxicol Environ Saf 61:287-312

Rajotte JW and Couture P. 2002. Effects of environmental metal contamination on the condition, swimming performance, and tissue metabolic capacities of wild yellow perch (Perca flavescens). Can J Fish Aquat Sci 59:1296-304 


\section{Metal Effects on Growth and Condition in Wild Yellow Perch}

Rennie MD, Collins NC, Shuter BJ, et al. 2005. A comparison of methods for estimating activity costs of wild fish populations: More active fish observed to grow slower. Can J Fish Aquat Sci 62:767-80

Scott WB and Crossman EJ. 1973. Freshwater Fishes of Canada. Fisheries Research Board of Canada, Ottawa, ON, Canada

Sherwood GD, Rasmussen DJ, Rowan DJ, et al. 2000. Bioenergetic costs of heavy metal exposure in yellow perch (Perca flavescens): In situ estimates with a radiotracer $\left({ }^{137} \mathrm{Cs}\right)$ technique. Can J Fish Aquat Sci 57:441-50

Sherwood GD, Pazzia I, Moeser A, et al. 2002a. Shifting gears: Enzymatic evidence for the energetic advantage of switching diet in wild-living fish. Can J Fish Aquat Sci 59:229-41

Sherwood GD, Kovecses J, Hontela A, et al. 2002b. Simplified food webs lead to energetic bottlenecks in polluted lakes. Can J Fish Aquat Sci 59:1-5

Taylor LN, McFarlane WJ, Pyle GG, et al. 2004. Use of performance indicators in evaluating chronic metal exposure in wild yellow perch (Perca flavescens). Aquat Toxicol 67:371-85 
Copyright of Human \& Ecological Risk Assessment is the property of Taylor \& Francis Ltd and its content may not be copied or emailed to multiple sites or posted to a listserv without the copyright holder's express written permission. However, users may print, download, or email articles for individual use. 